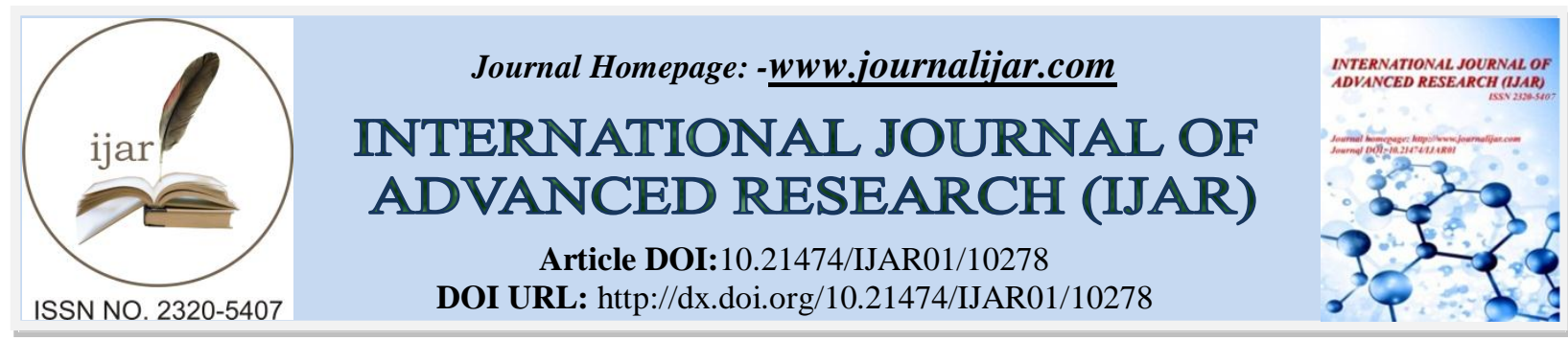

RESEARCH ARTICLE

\title{
PARTIAL ANOMALOUS PULMONARY VENOUS RETURN ASSOCIATED WITH SINUS VENOSUS ATRIAL SEPTAL DEFECT IN ELDERLY WOMEN: ABOUT ONE CASE AND LITERATURE REVIEW
}

\section{Jihad Raoui MD ${ }^{1}$, Bouthayna Mesmoudi $\mathrm{MD}^{2}$, Elizabeth O. Ugoani $\mathrm{MD}^{3}$, Harrak Safae $\mathrm{MD}^{4}$ and Cherti Mohamed DM ${ }^{5}$}

1. Resident Doctor Cardiology B Department, Ibn Sina Teaching Hospital Rabat Postal address: Avenue Mohamed V Lotissement Melk ALLAH Number 27/8 Temara 12000.

2. Resident Doctor Cardiology Center in the Mohammed V Military Instruction Hospital of Rabat. Postal address: Rabat 10000.

3. Resident Doctor Cardiology A Department, IbnSina Teaching Hospital Rabat Postal address: 91 Rue Azzouza Beaucite Hay Nahda 4 Rabat.

4. Resident Doctor Cardiology B Department, Ibn Sina Teaching Hospital Rabat Postal address: Rabat 10000.

5. Assistant Head of Department Cardiology B Department, Ibn Sina Teaching Hospital Rabat Postal address: Rabat 10000

\section{Manuscript Info}

\section{Manuscript History}

Received: 23 November 2019

Final Accepted: 25 December 2019

Published: January 2020

Key words:-

Partial Anomalous Pulmonary Venous Return, Sinus Venosus Atrial Septal Defect, Coronary Sinus

\begin{abstract}
Partial anomalous pulmonary venous return is a rare congenital defectthataffects one or more right or left-sided pulmonary veins. An association of this anomaly with sinus venosus atrial septal defect may also be seen. In this paper, we have reported an unique partial anomalous pulmonary venous return case associated with sinus venosus atrial septal defect discovered in an elderly woman who presented a right heart failure.

Abbreviations: Interauricular communications (CIA); superior vena cava (SVC) ; Partial Anomalous Pulmonary Venous Return (PAPVR); Inte-atrial septum (AIS); atrial septal defect (ASD); sinus venosus atrial septal defect (SVASD).
\end{abstract}

Copy Right, IJAR, 2020,. All rights reserved.

\section{Introduction:-}

Interauricular communications (CIA) are the most common heart defects in adults. Sinus venosus atrial septal defect is a type of interauricular communication located at the upper part of the interatrial septum, close to the superior vena cava (SVC) and is often associatedto a right upper abnormal pulmonary venous return. This type of CIA cannot be closed by percutaneous procedures, as there is no upper edge. Unlike the ostium secundum CIA, there is a male predominance.

Partial Anomalous Pulmonary Venous Return (PAPVR) is a rare congenital defect which is described in $0.4-0.7 \%$ of autopsies [1]. Anomalous venous return can contain one or more right- or left-sided pulmonary veins draining into the coronary sinus, right atrium or systemic veins [2].

Case Report:-

A 69-year-old-lady with no cardiovascular risk factors and no history of disease, was admitted to the hospital for a

Corresponding Author:- Jihad Raoui MD

Address:- Resident Doctor Cardiology B Department, Ibn Sina Teaching Hospital Rabat Postal address: Avenue Mohamed V Lotissement Melk ALLAH Number 27/8 Temara 12000. 
NYHA class III dyspnea of four weeks duration and edema of the lower limbs . The cardiovascular examination revealed a pulmonarysystolic ejection murmur, a fixed duplication of pulmonary B2 and a diastolic bearing at the tricuspid focal spot.

A right branch bundle block and a low voltage were observed on the electrocardiography. The transthoracic echocardiography revealed an expansion of the right heart cavities with a pulmonary arterial hypertension, the presence of sinus venosus atrial septal defect which measured $10 \mathrm{~mm}$; and an expansion of the coronary sinus which measured $56 \mathrm{~mm}$, suspecting an anomalous pulmonary venous return to coronary sinus. The transthoracic echocardiography also found a medium pericardial effusion (fig 1 and 2).

The transesophageal echocardiography confirmed the diagnosis, showing the presence of Sinus venosus atrial septal defect and an anomalous pulmonary venous return to coronary sinus.

The surgery was scheduled by the cardiovascular surgery department.

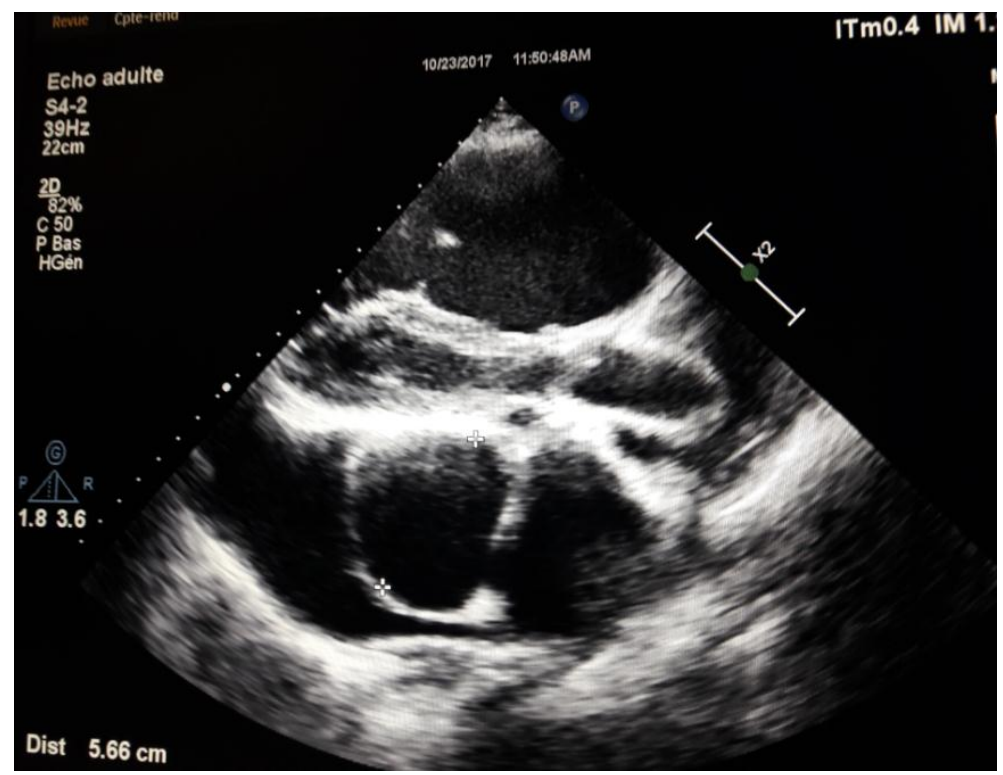

Figure 1:-Transthoracic echocardiography showing the persistence of the coronary sinus wich is very dilated, measuring $56 \mathrm{~mm}$.

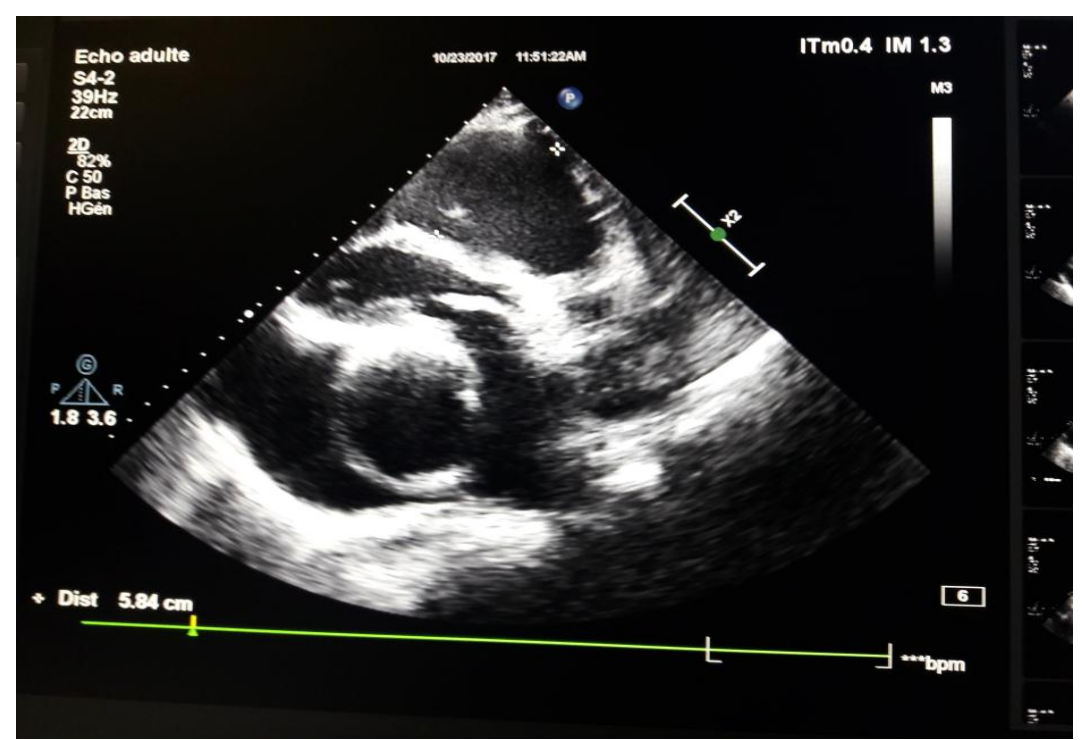

Figure 2:- Transthoracic echocardiography showing the dilated right ventricule which measures $58 \mathrm{~mm}$. 


\section{Discussion:-}

Partial Anomalous Pulmonary Venous Return (PAPVR) is a congenital defectthat involves the drainage of one to three pulmonary veins into the right-sided circulation, creating a partial leftto-right shunt [3]. It consists in a persistence of an embryonic anastomosis between the pulmonary veins and systemic venous plexus resulting in one or more anomalous pulmonary veins [4]. In pediatric studies, the PAPVR has been reported to be twice as common in men as in women and more frequently arising from the right (90\%) than the left upper lobe (10\%). Furthermore, the right upper lobe PAPVR is associated with SVASD in $80 \%$ to $90 \%$ of cases and ostium primum atrial septal defect in $10 \%$ to $15 \%$ of cases. It is presumed that "unroofing" the right superior pulmonary vein into the SVC during embryologic development produces a combination of anomalous return and atrial septal defect (ASD) [5].

Depending on the severity of the left to right shunting, we can find dyspnea, palpitation associated with atrial arrhythmias, symptoms of the right-sided heart failure and pulmonary hypertension in PAPVR patients [6]. The diagnosis cannot be done until adulthood in many of the patients. Theyoung symptomatic patients have more serious diseases and more congenital malformations thatrequire surgery. However, when PAPVR is recognised in adults, it may be manifested in subclinical or mild disease with a few associated anomalies [3]. Our patient had signs of right heart failure with a dilatation of right cavities.

The transesophageal echocardiography has an important role in the diagnosis of PAPVR and ASD [4], and its diagnosis power is better than the transthoracic echocardiography. Because of its technical advantages such as the short distance between the probe and the defect, longitudinal and short-axis images, and three-dimensional reconstruction's ability that are essential for identifying the pulmonary-systemic venous connection, the exact localization of the defect, the transesophageal echocardiography currently represents the most sophisticated diagnostic method for the morphologic evaluation of ASDs.

Furthermore, the intravascular ultrasonography has also similar benefits for the diagnosis of ASDs. However, the cross sectional imaging is the method of choice for the diagnosis of the PAPVR with or without ASD. The presence, trajectory, number of the anomalous pulmonary veins and probable associated cardiovascular defects can be detected. Contrast-enhanced CT and CTA are ideal for this aim, allowing rapid data acquisition with high resolution and wide anatomic extent [7]. Moreover, enhanced magnetic resonance angiography and cardiac magnetic resonance imaging also provide high spatial resolution for the evaluation of cardiac defects and great vessels such as pulmonary veins and arteries. Three-dimensional reconstructions which provide elaborate anatomic information can be achieved with magnetic resonance angiography [8].

Surgical treatment may be considered in patients who have isolated PAPVR and signs of right ventricular overload.This surgery can be performed with low morbidity and mortality by qualified surgeons, with improvement in the right ventricular size and pulmonary pressures in most cases [2]. The aim of surgical repair is to close the defect in the interatrial septum and normalize the systemic and pulmonary venous drainage. There are various surgical techniques for treating PAPVR with or without ASD such as patch techniques, and Warden's technique [2, $9,10]$.

\section{Conclusion:-}

Partial Anomalous Pulmonary Venous Return is a rare defect of the systemic venous return. This diagnosis should be suspected if a dilated coronary sinus is visualized by echocardiography and confirmed by cardiac angio-magnetic resonance imaging.

\section{Bibliography:-}

1. HEALEY JE Jr (1952) An anatomic survey of anomalous pulmonary veins: their clinical signifiance. J ThoracSurg. 23: 433-444.

2. Majdalany DS, Phillips SD, Dearani JA, Connolly HM, Warnes CA (2010) Isolated partial anomalous pulmonary venous connections in adults: twentyyear experience. Congenit Heart Dis 5: 537-545.

3. Ho ML, Bhalla S, Bierhals A, Gutierrez F (2009) MDCT of partial anomalous pulmonary venous return (PAPVR) in adults. J Thorac Imaging 24: 89-95.

4. Ammash NM, Seward JB, Warnes CA, Connolly HM, O’Leary PW, et al. (1997) Partial anomalous pulmonary venous connection: diagnosis by transesophageal echocardiography. J Am CollCardiol 29: 1351 -1358. 
5. Fraser RS, Muller NL, Colman N. Developmental anomalies affecting the pulmonary vessels. In: Fraser RS, Muller NL, eds. Diagnosis of Diseases of the Chest. (4thedn). Philadelphia: Saunders, 1999.

6. Alsouf B, Cai S, Van Arsdell GS, Williams WG, Caldarone CA, et al. (2007) Outcomes after surgical treatment of children with partial anomalous pulmonary venous connection. Ann ThoracSurg 84: 2020-2026.

7. Choe YH, Kang IS, Park SW, Lee HJ (2001) MR imaging of congenital heart diseases in adolescents and adults. Korean J Radiol 2: 121-131.

8. de Roos A, Roest AA (2000) Evaluation of congenital heart disease by magnetic resonance imaging. EurRadiol 10. 2-6.

9. KIRKLIN JW, ELLIS FH Jr, WOOD EH (1956) Treatment of anomalous pulmonary venous connections in association with interatrial communications. Surgery 39: 389-398.

10. Warden HE, Gustafson RA, Tarnay TJ, Neal WA (1984) An alternative method for repair of partial anomalous pulmonary venous connection to the superior vena cava. Ann ThoracSurg 38: 601-605. 